ARTICLE OPEN

\title{
Tomographic mapping of the nanoscale water-filled pore structure in corroded borosilicate glass
}

\author{
Daniel E. Perea $\mathbb{D}^{1,4 凶}$, Daniel K. Schreiber $\mathbb{D}^{2,4 凶}$, Joseph V. Ryan ${ }^{2}$, Mark G. Wirth ${ }^{1}$, Lu Deng ${ }^{3}$, Xiaonan Lu ${ }^{3}$, Jincheng Du ${ }^{3}$ and \\ John D. Vienna ${ }^{2}$
}

Cryo-based atom probe tomography has been applied to directly reveal the water-solid interface and hydrated corrosion layers making up the nanoscale porous structure of a corroded borosilicate glass in its native aqueous environment. The analysis includes morphology and compositional mapping of the inner gel/glass interface, isolation of a tomographic sub-volume of the tortuous water-filled gel, and comparison of the gel structure with simulations. The nanoscale porous structure is qualitatively consistent with that of the molecular dynamics simulation, enabling in greater confidence in both interrogations. Comparison of the gel/glass interface between desiccated and cryogenically preserved samples reveals consistently abrupt B dissolution behavior and quantitative differences in the apparent $\mathrm{H}$ ingress into the glass. These comparisons give some guidance to future experimental approaches to understanding glass corrosion behavior. More broadly, the cryogenic preservation and 3D visualization of the native water/solid structure in $3 \mathrm{D}$ at the nanoscale has direct relevance to a wide range of materials systems beyond glass science.

npj Materials Degradation (2020)4:8; https://doi.org/10.1038/s41529-020-0110-5

\section{INTRODUCTION}

The liquid-solid interface plays an essential role in many phenomena encountered in biological, chemical, and physical processes relevant to both fundamental and applied science; corrosion is one major globally-relevant area of science that has a profound socioeconomic impact. The corrosion of metal in the presence of moisture results from reduction/oxidation (redox) reactions at a metal surface and is, for example, estimated to cost the United States hundreds of billions of dollars per year within the infrastructure, utilities, transportation, production and manufacturing, and government sectors ${ }^{1}$. Corrosion also has a major environmental impact through the unintentional release of heavy metals ${ }^{2}$, including radionuclides ${ }^{3}$, into surrounding bodies of water and soil environments negatively affecting the health of local life. The further development of corrosion mitigation strategies requires deep insight into the physiochemical processes that occur at the reacting liquid-solid interface. However, the liquid-solid interface represents a technical challenge for highresolution microscopy as liquids are generally incompatible with a broad range of analytical tools that require high to ultrahigh vacuum conditions. One strategy to preserve and probe the liquidsolid interface is to cryogenically solidify the liquid. By doing so, local ionic chemical gradients, surface composition, and morphology can all be preserved within the solid water structure, making it more amendable to vacuum-based high-resolution imaging analyses. Following work by our group to develop both the hardware ${ }^{4}$, and specimen handling and preparation protocols of cryogenically-cooled specimens ${ }^{5}$, the work here reports on local atom-by-atom composition gradients within a water-filled nanoporous corroded glass using cryogenic atom probe tomography (cryo-APT). Using these newly developed cryogenic tools reveals surprising insights into the corroded glass structure and corrosion processes that were previously unobtainable by conventional microscopy approaches.
Borosilicate glasses are used to immobilize many nuclear wastes ${ }^{6}$. However, the durability of glass is not an intrinsic material property, but rather it reflects the evolving coupled response of a glass to changing aqueous environmental conditions ${ }^{7}$. Uncertainties in the durability of waste glasses over geologic timescales have resulted in conservative performance estimates and expensive repository designs. The environmental degradation of glass has been a topic of study for decades ${ }^{8-11}$, but the fundamental mechanisms and rate limiting steps of glass corrosion are still debated ${ }^{7,12,13}$. This fundamental knowledge gap results in overly conservative performance models and prohibits the design of waste glasses with targeted performance ${ }^{14}$.

The aqueous corrosion of glass results in the formation of structurally and compositionally distinct layers known collectively as altered glass. Several distinct processes describe the overall glass corrosion. Aqueous species $\left(\mathrm{H}_{3} \mathrm{O}^{+}\right.$and/or $\left.\mathrm{H}^{+}\right)$exchange with ionic species in the solid glass, usually alkali ions (e.g., $\mathrm{Na}^{+}, \mathrm{Li}^{+}$, $\left.\mathrm{K}^{+}\right)$, forming an ion exchange layer. Hydrogenous species $(\mathrm{H} 2 \mathrm{O}$, $\mathrm{H}^{+}, \mathrm{HO}^{-}, \mathrm{H}_{2} \mathrm{O}$ ) can also hydrolyze the directionally connected glass network components and eventually dissolve these components by hydrolyzing the last bridging oxygen bond ${ }^{7}$. Boron species are typically the easiest to hydrolyze and dissolve leaving a network rich in hydrated silica and alumina species. This material restructures to form a hydrolyzed aluminosilicate amorphous gel. Studies of the nature of this gel have shown a layered structure that is likely to dynamically change with conditions and time ${ }^{15,16}$. Ngo et al. ${ }^{17}$ identified two distinct gel-layers in altered international simple glass (ISG) using elliptical spectroscopy-an outer gel with higher porosity and an inner gel with lower porosity. Selective nanoscale characterization of the structure, composition, and chemistry of both the corroding glass and surrounding water solvent and the interface between them is needed to reveal the controlling processes that can enable scientific-based corrosion

\footnotetext{
'Environmental Molecular Sciences Laboratory, Earth and Biological Sciences Directorate, Pacific Northwest National Laboratory, Richland, WA 99352, USA. ${ }^{2}$ Energy and Environment Directorate, Pacific Northwest National Laboratory, Richland, WA 99352, USA. ${ }^{3}$ Department of Materials Science and Engineering, University of North Texas, Denton, TX 76203, USA. ${ }^{4}$ These authors contributed equally: Daniel E. Perea, Daniel K. Schreiber. ${ }^{凶}$ email: daniel.perea@pnnl.gov; daniel.schreiber@pnnl.gov
} 
models that can inform waste form design to predict performance over geologic timescales.

Here, we apply a novel approach of cryogenically preparing specimens for APT analysis ${ }^{5}$, enabling the nanoscale tomographic analysis within compositionally and structurally distinct hydrated regions of the altered glass in its native aqueous environment. Specifically, we report solid and dissolved ion composition gradients across the outer gel (OG)/inner gel (IG)/glass interface regions, as well as map the $3 \mathrm{D}$ nanoscale porous structure of the inner gel. We anticipate that this cryo-based specimen preparation and analysis approach can be further applied to the study of liquid-solid chemistry within nano-confined geometries and buried interfaces. For example, an extension of the work presented here can be applied to map ionic and macromolecular gradients across liquid-solid interface of biological membranes; hydrated phases within bio and geominerals; ionic distributions across liquid-solid interface within nano-confined volumes such as crack tips or advanced battery materials.

\section{RESULTS}

Cryo-FIB preparation and APT analysis of altered glass

The glass sample analyzed in this study is a corroded piece of SON68 boroaluminosilicate glass, which is the non-radioactive surrogate for the French R7T7 nuclear waste glass ${ }^{18}$. Specific details of the glass specimen and corrosion are described in the Methods section. Site-specific focused ion beam (FIB) trenching and APT specimen extraction and sharpening of specimens targeting the native water/glass region were made possible using a cryo-specific FIB liftout procedure described elsewhere ${ }^{19}$. Specific details of the specimen preparation are described in the Methods section. A modified specimen shuttle carrier suitcase from Quorum Technologies was used to transfer specimens between the cryo-FIB and APT (passive cooling and modest passive vacuum $\left.\left[\sim 1 \times 10^{-5} \mathrm{mbar}\right]\right)$ to prevent solid water sublimation or frost accumulation during transfer $(\sim 90 \mathrm{~s}$ under passive conditions) ${ }^{4}$.

The aqueous corrosion of glass results in the formation of structurally and compositionally distinct layers known collectively as altered glass. In Fig. 1a, a cross sectional cryogenic scanning electron microscope (SEM) image shows a portion of a corroded glass particle embedded in the frozen corroding water solution. The altered glass (corrosion) layer exhibits slightly darker contrast than the surrounding glass and has an average thickness $\sim 300 \mathrm{~nm}$. This alteration layer and pristine glass core are preserved in the final needle-shaped APT specimen (Fig. 1b). Two successful APT specimens were produced from this single particle; one of which targeted the bulk solid water/outer gel interface and is described in a separate method-focused manuscript $^{5}$, and one which targeted the hydrated nanoporous inner gel/pristine glass interface and is the subject of the work presented here.

A representative portion of the mass-to-charge-state ratio spectrum (mass spectrum) obtained by APT of the porous inner gel + solution and underlying pristine glass is shown in Fig. 1c (full spectra and mass ranges for identified ions are included in Fig. S1 and Table 1 in Supplementary Information). The composition of the pristine glass is dominated by the primary glass components ( $\mathrm{Si}, \mathrm{O}, \mathrm{Li}, \mathrm{Na}, \mathrm{Ca}, \mathrm{B}$ and $\mathrm{Al})$. Notably, water fragments are also detected as the series $\mathrm{HO}^{1+}, \mathrm{H}_{2} \mathrm{O}^{1+}, \mathrm{H}_{3} \mathrm{O}^{1+}$ (highlighted in blue as $\mathrm{H}_{\mathrm{x}} \mathrm{O}^{1+}$ between $17-19 \mathrm{Da}$ ) and $\mathrm{SiOH}^{+}$at $45 \mathrm{Da}$, which are consistent with APT analyses of the solid water ice ${ }^{20}$ and hydrated silica from the gel. Notably, peaks typically associated with frost ice contamination at mass-to-charge-state ratios of $37 \mathrm{Da}, 55 \mathrm{Da}$, and $73 \mathrm{Da}$ associated with $\left[\left(\mathrm{H}_{2} \mathrm{O}\right)_{x} \cdot \mathrm{H}_{3} \mathrm{O}\right]^{+}$where $x=1-3$ respectively, which can occur during cryo specimen transfer between the FIB and the atom probe, are absent ${ }^{5}$.
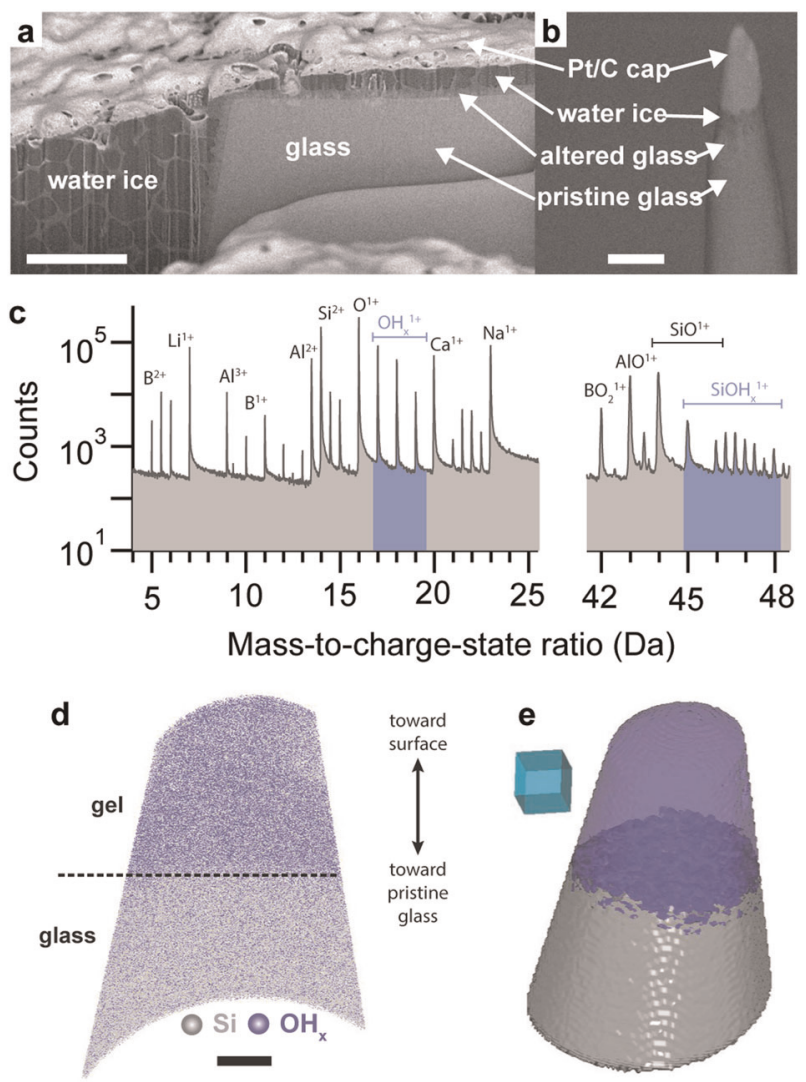

Fig. 1 Cryo-FIB specimen preparation and Cryo-APT analysis of altered glass. a Cryo-FIB prepared cross section SEM image of glass particle embedded in water ice. Scale bar $=3 \mu \mathrm{m}$. b Specimen shaped into needle morphology prior to APT analysis with the relevant regions labeled. Scale bar $=500 \mathrm{~nm}$. c Selected region of mass spectrum showing major ions detected. Water and hydrated Si-oxide are highlighted in blue. d APT reconstruction shown as an $8 \mathrm{~nm}$ thick slice. Only $\mathrm{Si}$ and $\mathrm{H}_{\mathrm{x}} \mathrm{O}^{1+}$ ions with $x=2$ and 3 are shown for visual clarity of the glass/gel heterointerphases. Scale bar $=$ $10 \mathrm{~nm}$. e APT reconstruction shown with the water-rich region and Si-rich regions outlined by a 4 at. $\% \mathrm{H}_{2} \mathrm{O}$ isoconcentration surface. Scale cube is $10 \times 10 \times 10 \mathrm{~nm}^{3}$.

The precise relative position of each detected ion making up the mass spectrum is known providing a means to 3D compositional mapping. The element-specific 3D atom map shown in Fig. 1d qualitatively reveals a heterophase interface. Within the thin reconstruction slice ( $8 \mathrm{~nm}$ image depth), waterrelated species (blue) clearly partition to the upper portion of the reconstruction (i.e., closer to the exposed surface of the specimen), consistent with the water-filled porous gel region. An isoconcentration surface of 4 ion $\% \mathrm{H}_{2} \mathrm{O}^{1+}$ further delineates the water-rich and water-poor regions (Fig. 1e). Although this horizontally bisecting interface is roughly planar, close inspection reveals it is not smooth.

Further inspection of the ionic speciation within the APT data reveals clues into the nature of the altered glass structure. Figure 2 presents element-specific distribution maps of ionic signals from the APT mass spectrum, which are further quantified by a 1D ionic composition profile. Four distinct regions are apparent. Near the specimen apex (left hand side), Ga implantation and FIB damage result in an altered speciation. This is followed by two distinct gel regions, nominally described as outer gel (OG) and inner gel (IG), and finally pristine glass. The IG shows a distinctly higher composition of $\mathrm{O}^{+}$than the OG. This is consistent with a denser 


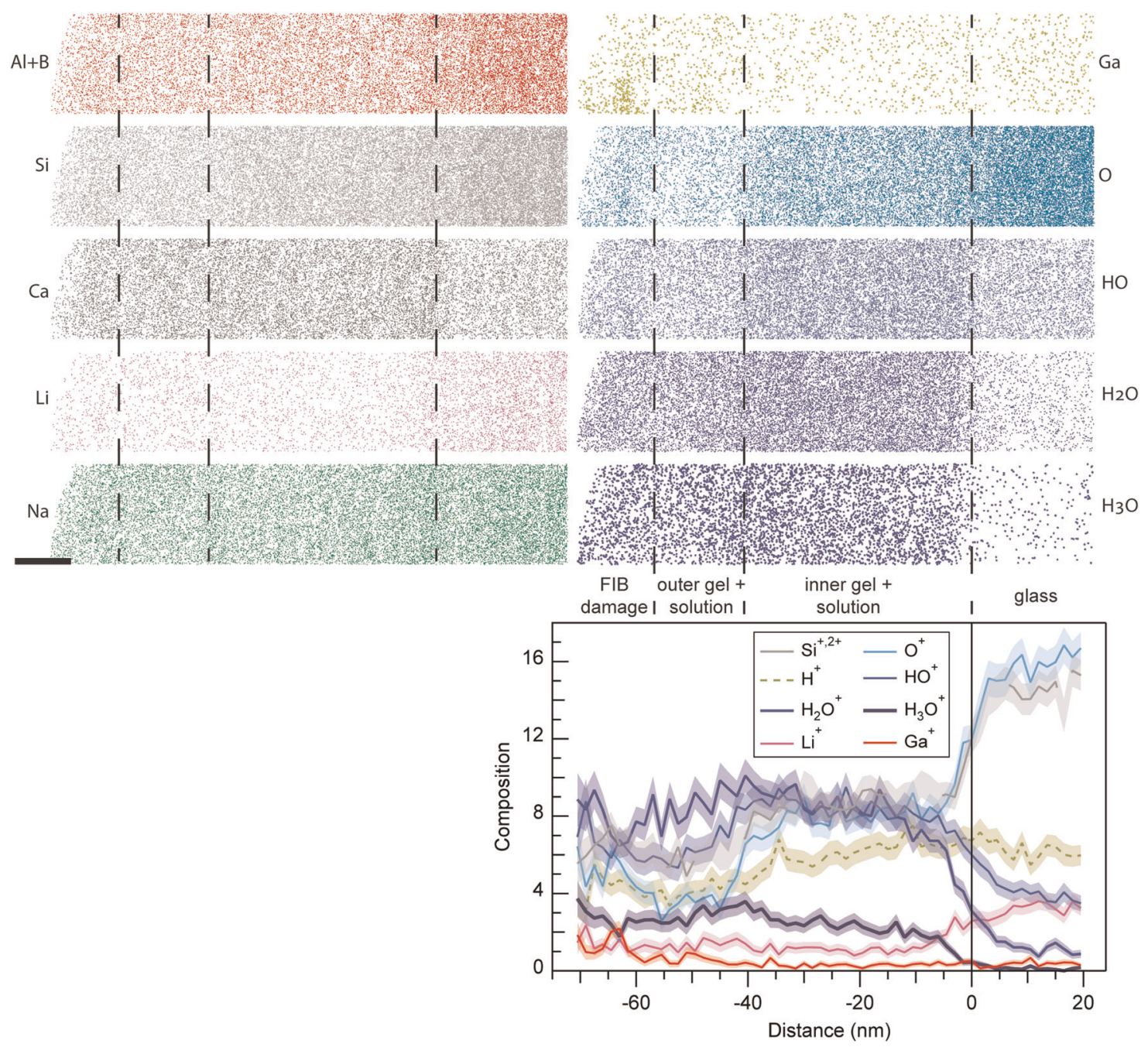

Fig. 2 Tomographic mapping of the hydrated heterophase interface of altered glass. lonic speciation in APT data collected from cryogenically prepared glass gel. Element-specific ion maps (10 nm depth) and corresponding quantitative composition profile (ionic \%). Scale $\mathrm{bar}=10 \mathrm{~nm}$. Four distinct regions are delineated: the outer FIB damaged gel, outer porous gel, inner dense gel, and pristine glass. Shaded bands represent $1 \sigma$ error based on counting statistics.

hydrated silica network in the IG, resulting in less free water that typically evaporates as larger $\mathrm{H}_{x} \mathrm{O}$ species. Indeed, the $\mathrm{H}_{x} \mathrm{O}^{+}$signal increases proportionally versus the $\mathrm{Si}$ and $\mathrm{O}$ signals in the $\mathrm{OG}$, which is expected to have a more open and water-filled porous structure. This signal decreases again within the FIB-damaged region where sublimation of water ice is possible during sample preparation.

The unique ability to prepare, transfer, and analyze cryogenically-prepared specimens may also reveal possible artifacts that have been introduced by traditional sample rinsing and desiccation performed as part of conventional room temperature specimen preparation. A comparison of APT composition profiles across the pristine glass/IG interface from cryogenic and conventional FIB sample preparation of the same glass is presented in Fig. 3. These are reported as decomposed atomic compositions (Fig. 3a, b) and as ionic compositions (Fig. 3c, d). The atomic profiles reveal similar key features in both datasets. The IG is $\mathrm{H}$-rich and alkali poor and the interface between glass and the IG is delineated by an abrupt change in $\mathrm{Al}+\mathrm{B}$ content, which has been ascribed to a $\mathrm{B}$ dissolution front. Hydrogen penetrates into the glass in both cases, which has been described alternatively as evidence of ion exchange ${ }^{21}$ or as a possible field evaporation artifact of the APT technique ${ }^{22}$. The qualitative consistency of this observation for cryogenic and room temperature preparation make apparent the $\mathrm{H}$ penetration is not a preparation artifact, although there is a clear quantitative difference with more $\mathrm{H}$ being preserved in the cryo-sample. Furthermore, a field evaporation artifact (e.g., preferential evaporation or retention of a specific species) should show opposite behavior depending on evaporation sequence ${ }^{23,24}$. Here we note that similar $\mathrm{H}$ penetration was observed in previous work ${ }^{21}$ in the opposite evaporation sequence, which proves it is also not a simple field evaporation artifact. Additionally, the relative $\mathrm{H}$ distribution can also be affected by the local electrostatic conditions of the specimen during field evaporation across heterointerphases ${ }^{25-27}$. To assess this, we provide in Fig. S2 of the Supplemental Information the APT voltage curve across the glass/gel interface for specimens prepared from cryogenically frozen and desiccated samples. Importantly, there is no discernable voltage change across the gel/glass interface for the cryogenically prepared specimen, suggesting that there are no apparent evaporation field differences causing selective evaporation or spatial aberrations. On the other hand, comparison of the voltage curves for desiccated specimen geometries show a dramatic voltage drop at the interface regardless of evaporation sequence and reinforces the importance of the cryogenically prepared specimen. Taken altogether, these data clearly show that $\mathrm{H}$ does indeed penetrate 

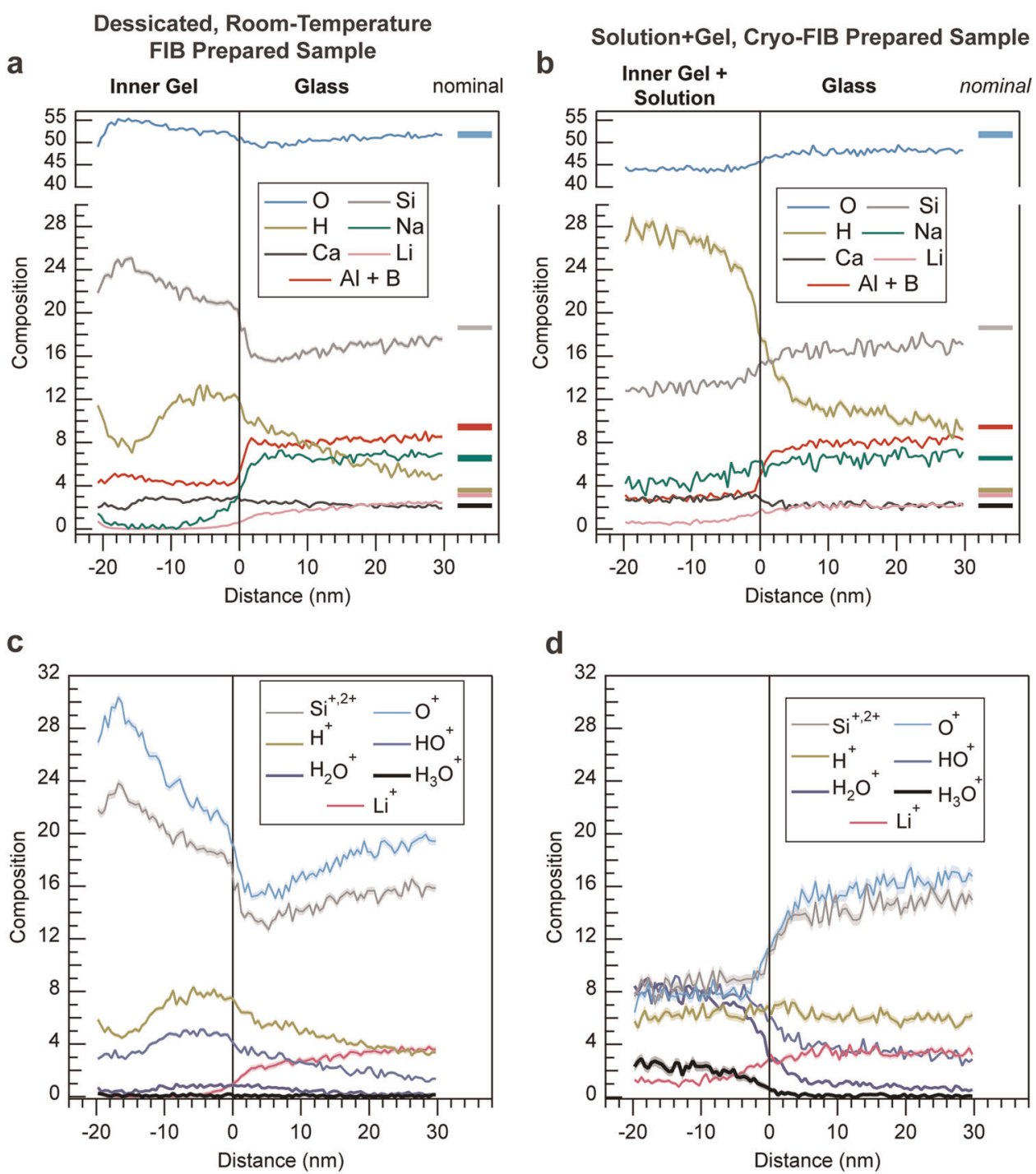

Fig. 3 Comparing elemental distributions in traditional room temperature prepared and cryogenically prepared altered glass specimens. Decomposed elemental (top) and ionic (bottom) \% composition profiles across the gel/glass interface for specimens prepared at (a, c) room temperature desiccated specimens, and (b, d) cryogenic conditions. Nominal APT-measured atomic compositions of the bulk glass are annotated to the right. Shaded bands represent $1 \sigma$ error based on counting statistics.

beneath the altered gel into the pristine glass corroded under these corrosion conditions.

A close inspection of the ionic species measured by cryogenic and room temperature preparation also provides important insights for delineating dissolved species in solution from the nanoporous gel within the mixed IG + solution region of the cryogenically preserved sample. This is critical for fully leveraging the 3D nature of the APT data to reveal the structure and morphology of the gel itself. While the desiccated gel is dominated by $\mathrm{Si}^{2+}, \mathrm{O}^{+}, \mathrm{H}^{+}$and $\mathrm{HO}^{+}$the signals from the waterfilled gel of the cryogenically prepared specimen show significantly higher composition of $\mathrm{H}_{2} \mathrm{O}^{+}$and $\mathrm{H}_{3} \mathrm{O}^{+}$that originate from solid water trapped within the porous IG. This is also consistent with the interpretation of Fig. 2, where these larger $\mathrm{H}_{x} \mathrm{O}$ species increase proportionally relative to the $\mathrm{Si}$ and $\mathrm{O}$ species in the greater porosity of the OG region.

The ability to tomographically-map composition and distinguish solution-bound species from the glass network provides a means to quantitatively describe the nanoporous structure of the gel. To do this, care has to be taken to define which species to be used to define a surface to spatially delineate between the solution phase from the hydrated silicate gel network. The signals from $\mathrm{Li}$ and $\mathrm{Na}$ which originate from dissolved species in the water, may have nanoscale mobility during APT field evaporation ${ }^{28}$, and thus are poor candidates for delineating gel structure. Furthermore, these alkali distributions may have been impacted by the potential crystallization of solid water during plunge freezing; it is unknown if the solid water is crystalline or amorphous ice within the nanoscale pores of the gel. Future experiments utilizing faster freezing approaches (e.g., high pressure freezing ${ }^{29}$ ) are needed to improve confidence in the distribution of these species. Based on these comparisons, $\mathrm{H}_{2} \mathrm{O}^{+}$and $\mathrm{H}_{3} \mathrm{O}^{+}$are the best candidate signatures for creating isoconcentration surfaces that outline the water-filled porous network of the gel and are presented within a $20 \times 20 \times 20 \mathrm{~nm}^{3}$ subsection of the inner gel as shown in Fig. 4 a. These surfaces, drawn at 9 ion $\% \mathrm{H}_{2} \mathrm{O}^{+}+\mathrm{H}_{3} \mathrm{O}^{+}$, separate regions of high-water content (blue) from low-water content (gray). This visualization reveals a network of interpenetrating water channels through the IG region of the altered glass. The volume fraction of each phase is approximately $50 \%$, in line with nominal expectations of the gel's porosity ${ }^{30}$. 
a

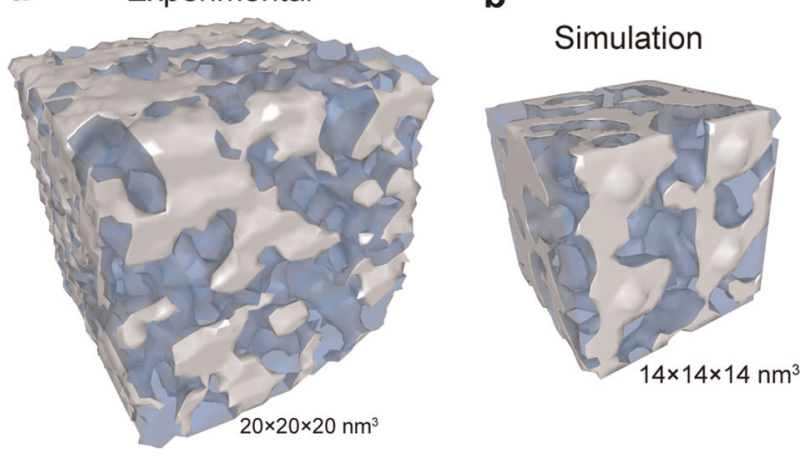

Fig. 4 Visualization of nanoscale pore structure. 3D visualization of nanoscale heterogeneity within the inner gel by a experimental cryo-APT and $\mathbf{b}$ MD simulations. Isoconcentration surfaces delineate interpenetrating channels of water-rich (blue) and water-poor (gray) regions in both datasets.

The ability to directly map the nanoscale water-filled porous network of a corroded media can also provide experimental guidance to developing rational corrosion models. As a qualitative test, a molecular dynamics (MD) simulation of a corroded glass structure from a simple 6-component glass, with the same molar ratios of SON68, and commonly known as ISG ${ }^{6}$, was compared to the cryo-based experiments; details of the MD simulation are found in the Methods section. A visual comparison between the experimental (Fig. 4a) and the simulated porous structure (Fig. 4b) show good qualitative agreement, wherein about $50 \%$ of the reconstructed volume is identified as interpenetrating water-rich channels. We note that a detailed quantitative comparison between the experimentally mapped and the simulation modeled gel structure will be the subject of future investigations. In particular, characterization of a ground truth experimental sample is needed with a known and well-defined pore structure such as Vycor $^{\circledR 31}$. This will establish needed confidence to further mine the reconstructed gel structure for the tortuosity and interconnectedness that will inform models of transport behavior through these nanoscopic features. For now, we simply state that the general structure and porous volume are comparable and also consistent with expectations from the glass corrosion literature ${ }^{32}$.

\section{DISCUSSION}

Considering the difficulty of the cryo-based analyses, it is useful to evaluate the strengths and limitations of the conventional (room temperature) APT analysis of glass corrosion. APT analysis of water-solid (water ice/OG) and highly porous layers (OG) must utilize cryogenic specimen preparation routes as preservation of the native water is inherent to their analyses. Conversely the IG/ glass interface is reasonably well reproduced via room temperature preparation. Quantitative differences at this interface are, however, problematic for mechanistic interpretation. Significantly more $\mathrm{H}$ is found penetrating the glass from cryogenic preparation (12 at. $\%$ at $5 \mathrm{~nm}$ ) versus room temperature ( 9 at. $\%$ at $5 \mathrm{~nm}$ ), while their respective alkali compositions are similar ( 2 at. $\%$ and 1.4 at. $\% \mathrm{Li}$, respectively). It is thus difficult to definitively state that the $\mathrm{H}$ originates from ion exchange versus some other explanation (e.g., neutral water diffusion ${ }^{33}$ ). Note that the incorporation of environmental hydrogen is suppressed in titanium-based specimens, which are known to have a high affinity for hydrogen incorporation, when prepared under cryogenic conditions in a $\mathrm{FIB}^{34}$. The fact that the desiccated sample apparently loses significant $\mathrm{H}$ during rising and drying suggests that some fraction of this $\mathrm{H}$ is weakly bound to the glass, which may suggest a mixture of ion exchange and water is present. The offset of inflection points for the $\mathrm{Li}$ and $\mathrm{B}$ profiles in Fig. 3b, $\mathrm{d}$ may support the detection of an ion exchange region with the Li profile extending about $14 \mathrm{~nm}$ $(\sim-7$ to $+7 \mathrm{~nm})$, and the $\mathrm{Al}+\mathrm{B}$ profile extending about $3 \mathrm{~nm}(\sim-1$ to $+2 \mathrm{~nm}$ ). Further data, particularly to reproduce these results quantitatively and under different corrosion conditions, are necessary to reach a more definitive conclusion. However, these data do provide further proof for $\mathrm{H}$ penetration into the glass, almost certainly from diffusion-controlled processes, in addition to the very abrupt $B$ profile that is again best described as a dissolution front.

In summary, we have reported the nanoscale composition and structure analysis of the various regions of a corroded glass using cryo-APT enabled by an innovative cryogenic specimen preparation and handling approach that is described elsewhere ${ }^{5}$. Via this unique cryogenic preparation approach, we were able to preserve the native structure and composition of water-filled altered glass to reveal the nanoscale structure of the porous silicate gel, as well directly map dissolved ion composition gradients within various compositionally and structurally distinct regions. We anticipate that extension of our approach can be further applied to the study of liquid-solid chemistry within nano-confined systems such as ionic and macromolecular gradients across biological membranes; hydrated phases within biominerals and geominerals; ionic distributions across liquid-solid interface within nano-confined volumes such as crack tips or advanced batteries.

\section{METHODS}

Glass Sample

The composition of the SON68 glass used in this study is (in mol\% oxide): $3.39 \mathrm{Al}_{2} \mathrm{O}_{3}, 14.02 \mathrm{~B}_{2} \mathrm{O}_{3}, 5.01 \mathrm{CaO}, 1.31 \mathrm{Fe}_{2} \mathrm{O}_{3}, 0.98$ combined lanthanide oxides, $4.60 \mathrm{Li}_{2} \mathrm{O}, 11.39 \mathrm{Na}_{2} \mathrm{O}, 52.69 \mathrm{SiO}_{2}, 2.15 \mathrm{ZnO}, 1.54 \mathrm{ZrO}_{2}$, and 2.93 other minor oxides. The glass was crushed and sieved to a nominal size of 30-75 $\mu \mathrm{m}$ and tested in deionized water at a nominal surface area to solution volume of $20,000 \mathrm{~m}^{-1}$. The glass was corroded in a PTFE lined stainless steel vessel at $90^{\circ} \mathrm{C}$ for approximately 6 years and is the subject of other studies by our group ${ }^{5,35}$. The conventional room temperature prepared sample was removed from an identical reactor vessel after 1117 days of alteration, rinsed twice with ethanol, and dried overnight in a $90^{\circ} \mathrm{C}$ oven. A small sample volume $(\sim 100 \mu \mathrm{L})$ of powder-containing water was extracted from the corrosion experiment vessel and held in a vial at room temperature before beginning the FIB-based specimen preparation.

\section{Cryo-FIB/SEM}

A Thermo Fisher Helios 600 Nanolab dual-beam focused ion beam/ scanning electron microscope (FIB/SEM) equipped with a modified Quorum PT-2010 cryo stage and specimen preparation station ${ }^{4}$ was used to cryogenically prepare needle-shaped APT specimens containing the corroding water media and an individual corroded glass particle. A full description of the unique cryo-FIB based specimen preparation procedure leading to the APT analysis described here is the subject of a separate method development-focused manuscript by Schreiber et al. ${ }^{5}$. In brief, $2 \mu \mathrm{L}$ of aqueous slurry containing corroded glass particles in their corroding water solution was drop cast from a micropipette onto a copper substrate and plunged into slush nitrogen. Using a shuttle device, the frozen sample was transferred under low vacuum into the cryo-FIB/SEM via a modified cryo-load lock and onto the FIB/SEM cold stage $\left(-189 \pm 2{ }^{\circ} \mathrm{C}, \sim 2 \times 10^{-6}\right.$ mbar), which is sufficient to prevent water sublimation during FIB processing. A cryogenically deposited bilayer of sputtered Pt metal and FIB gas injection system deposited organometallic Pt provided electrical grounding and surface protection against FIB damage. Site-specific FIB trenching and APT specimen extraction and sharpening targeting the native water/glass surface were made possible using cryo-specific FIB liftout procedures ${ }^{5}$. The Quorum shuttle carrier was used to transfer specimens between the cryo-FIB and APT (passive cooling and modest passive vacuum $\left[\sim 1 \times 10^{-5} \mathrm{mbar}\right]$ ) to prevent solid water sublimation or frost accumulation during transfer ( $\sim 90 \mathrm{~s}$ under passive conditions).

\section{Cryo-APT}

A LEAP 4000X HR (Cameca Instruments) atom probe tool that has been modified with an Environmental Transfer Hub (ETH $)^{4}$ and actively cooled 
cryogenic load lock $\left(\sim-165^{\circ} \mathrm{C}\right.$ and $\left.\sim 4 \times 10^{-8} \mathrm{mbar}\right)$ was used to facilitate environmentally-controlled specimen transfer of the cryogenicallyprepared APT specimens. APT analysis of the cryogenically prepared specimens proceeded similarly to room temperature prepared APT specimens of corroded glass ${ }^{21}$. Data collection parameters included UV laser pulsing $(\lambda=355 \mathrm{~nm})$ with a laser pulse energy of $150 \mathrm{pJ} / \mathrm{pulse}$ and a detection rate of $0.2 \%$ ( 0.002 detected ions per laser pulse). The sample was maintained at stage setpoint of $40 \mathrm{~K}$ and a nominal base pressure of $<3 \times 10^{-11}$ mbar during data collection, which prevents water sublimation from the specimen. Data reconstruction, visualization, and analyses utilized the IVAS software package version 3.8.0 (Cameca Instruments). The 3D composition space for isoconcentration surfaces was established with a voxel size of $0.5 \mathrm{~nm}$ and a delocalization of $1.5 \mathrm{~nm}$. Significant isobaric mass peak convolutions (i.e., overlap) exist for the complex SON68 glass. The most significant of these are ${ }^{11} \mathrm{~B}^{16} \mathrm{O}_{x+1}$ with ${ }^{27} \mathrm{Al}^{16} \mathrm{O}_{x}$, where $x=0,1,2$. In the presented data, we considered the combined signal as $\mathrm{B}+\mathrm{Al}$ unless otherwise explicated.

\section{Simulations}

The glass structure was formed through a simulated melt and quench process with MD simulations by using the DL_POLY package ${ }^{36}$. Effective partial charge pairwise potential with composition dependent boron related parameters to account for the composition dependent coordination change of boron were used in the simulations ${ }^{37,38}$. Details of the simulation procedure has been reported elsewhere ${ }^{15,39}$. An algorithm was developed to simulate the dissolution process by removing all $\mathrm{Na}$ and $\mathrm{B}$ atoms, $30 \% \mathrm{Ca}$ and free oxygen (oxygen not bonded to any $\mathrm{Si}, \mathrm{Al}$ or $\mathrm{Zr})^{15}$. The final gel structure, containing the elements Si-Al-Ca-Zr-O-H, was created by hydroxylation of the dangling bonds of the network forming polyhedral and then randomly adding water molecules into the void spaces within the glass network. This procedure mimics the diffusion, dissolution and reorganization processes that leads to a porous hydrated gel structure and shows similar features of the passivation gel layer structure as a result of silicate glass dissolution ${ }^{40}$. To further mimic the APT data, an additional $50 \%$ of all atoms were removed accounting for detector efficiencies, resulting in a final system of $\sim 68,000$ atoms forming a $14 \times$ $14 \times 14 \mathrm{~nm}^{3}$ volume of water-filled gel. These data were imported into the same APT analysis software to generate isoconcentration surfaces (9 ion\% $\mathrm{H})$ of the simulated gel structure.

\section{DATA AVAILABILITY}

The data that supports the results of the presented study are available from the corresponding author(s) upon request.

Received: 29 October 2019; Accepted: 13 February 2020; Published online: 18 March 2020

\section{REFERENCES}

1. Hansson, C. M. The impact of corrosion on society. Met. Mater. Trans. A 42a, 2952-2962 (2011).

2. Clozel, B., Ruban, V., Durand, C. \& Conil, P. Origin and mobility of heavy metals in contaminated sediments from retention and infiltration ponds. Appl. Geochem. 21, 1781-1798 (2006).

3. Handley-Sidhu, S., Keith-Roach, M. J., Lloyd, J. R. \& Vaughan, D. J. A review of the environmental corrosion, fate and bioavailability of munitions grade depleted uranium. Sci. Total Environ. 408, 5690-5700 (2010).

4. Perea, D. E., Gerstl, S. S. A., Chin, J., Hirschi, B. \& Evans, J. E. An environmental transfer hub for multimodal atom probe tomography. Adv. Struct. Chem. Imag. 3, 12 (2017).

5. Schreiber, D. K., Perea, D. E., Ryan, J. V., Evans, J. E. \& Vienna, J. D. A method for site-specific and cryogenic specimen fabrication of liquid/solid interfaces for atom probe tomography. Ultramicro 194, 89-99 (2018).

6. Gin, S. et al. An international initiative on long-term behavior of high-level nuclear waste glass. Mater. Today 16, 243-248 (2013).

7. Vienna, J. D., Ryan, J. V., Gin, S. \& Inagaki, Y. Current understanding and remaining challenges in modeling long-term degradation of borosilicate nuclear waste glasses. Int J. Appl. Glass Sci. 4, 283-294 (2013).

8. Ewing, R. C. Nuclear waste form glasses: the evaluation of very long-term behaviour. Mater. Technol. 16, 30-36 (2001)
9. Jantzen, C. M., Brown, K. G. \& Pickett, J. B. Durable glass for thousands of years. Int J. Appl. Glass Sci. 1, 38-62 (2010).

10. Mendel, J. E. Final report of the defense high-level waste leaching mechanisms program. PNL-5157/UC-70. (Pacific Northwest Laboratory, Richland, WA, 1984).

11. Werme, L. et al. Chemical corrosion of highly radioactive borosilicate nuclear waste glass under simulated repository conditions. J. Mater. Res. 5, 1130-1146 (1990).

12. Gin, S. et al. The controversial role of inter-diffusion in glass alteration. Chem. Geol. 440, 115-123 (2016).

13. Van Iseghem $P$, et al. GLAMOR - Or how we achieved a common understanding on the decrease of glass dissolution kinetics. In: Environmental Issues and Waste Management Technologies in the Materials and Nuclear Industries XII (eds. Cozzi A. \& Ohji T.) (John Wiley \& Sons, 2009).

14. Frankel, G. S. et al. A comparative review of the aqueous corrosion of glasses, crystalline ceramics, and metals. NPJ Mater. Degrad. 2, 15 (2018).

15. Collin, M. et al. Structure of international simple glass and properties of passivating layer formed in circumneutral $\mathrm{pH}$ conditions. NPJ Mater. Degrad. 2, 4 (2018).

16. Gin, S. et al. Dynamics of self-reorganization explains passivation of silicate glasses. Nat. Commun. 9, 2169 (2018).

17. Ngo, D. et al. Spectroscopic ellipsometry study of thickness and porosity of the alteration layer formed on international simple glass surface in aqueous corrosion conditions. NPJ Mater. Degrad. 2, 20 (2018).

18. Guittonneau, C., Gin, S., Godon, N., Mestre, J. P., Dugne, O. \& Allegri, P. A 25-year laboratory experiment on French SON68 nuclear glass leached in a granitic environment - First investigations. J. Nucl. Mater. 408, 73-89 (2011).

19. Thompson, K., Lawrence, D., Larson, D. J., Olson, J. D., Kelly, T. F. \& Gorman, B. In situ site-specific specimen preparation for atom probe tomography. Ultramicroscopy 107, 131-139 (2007).

20. Moody, M. P., Vella, A., Gerstl, S. S. A. \& Bagot, P. A. J. Advances in atom probe tomography instrumentation: Implications for materials research. MRS Bull. 41, 40-45 (2016).

21. Gin, S., Ryan, J. V., Schreiber, D. K., Neeway, J. \& Cabie, M. Contribution of atomprobe tomography to a better understanding of glass alteration mechanisms: Application to a nuclear glass specimen altered 25 years in a granitic environment. Chem. Geol. 349, 99-109 (2013).

22. Hellmann, R. et al. Nanometre-scale evidence for interfacial dissolutionreprecipitation control of silicate glass corrosion. Nat. Mater. 14, 307-311 (2015).

23. Larson, D. J., Prosa, T. J., Geiser, B. P. \& Egelhoff, W. F. Effect of analysis direction on the measurement of interfacial mixing in thin metal layers with atom probe tomography. Ultramicroscopy 111, 506-511 (2011).

24. Marquis, E. A., Geiser, B. P., Prosa, T. J. \& Larson, D. J. Evolution of tip shape during field evaporation of complex multilayer structures. J. Microsc-Oxf. 241, 225-233 (2011).

25. Chang, Y. H. et al. Quantification of solute deuterium in titanium deuteride by atom probe tomography with both laser pulsing and high-voltage pulsing: influence of the surface electric field. New J. Phys. 21, 40-45 (2019).

26. Mouton, I. et al. Quantification challenges for atom probe tomography of hydrogen and deuterium in Zircaloy-4. Microsc Microanal. 25, 481-488 (2019).

27. Sundell, G., Thuvander, M. \& Andren, H.-O. Hydrogen analysis in APT: methods to control adsorption and dissociation of $\mathrm{H}_{2}$. Ultramicro 132, 285-289 (2013).

28. Greiwe, G.-H., Balogh, Z. \& Schmitz, G. Atom probe tomography of lithium-doped network glasses. Ultramicro 141, 51-55 (2014).

29. Moor H. Theory and practice of high pressure freezing. In: Cryotechniques in Biological Electron Microscopy (eds Steinbrecht R. A. \& Zierold K.) (Springer, 1987).

30. Reiser, J. T., Parruzot, B., Weber, M. H., Ryan, J. V., McCloy, J. S. \& Wall, N. A. The use of positrons to survey alteration layers on synthetic nuclear waste glasses. J. Nucl. Mater. 490, 75-84 (2017).

31. Bentz, D. P., Garboczi, E. J. \& Quenard, D. A. Modelling drying shrinkage in reconstructed porous materials: application to porous Vycor glass. Model Simul. Mater. Sci. Eng. 6, 211-236 (1998).

32. Kaspar, T. C., Reiser, J. T., Ryan, J. V. \& Wall, N. A. Non-destructive characterization of corroded glass surfaces by spectroscopic ellipsometry. J. Non-Cryst. Solids 481, 260-266 (2018).

33. Tomozawa, H. \& Tomozawa, M. Diffusion of water into a borosilicate glass. J. NonCryst. Solids 109, 311-317 (1989).

34. Chang, Y. H. et al. Ti and its alloys as examples of cryogenic focused ion beam milling of environmentally-sensitive materials. Nat. Commun. 10, 942 (2019).

35. Wang, Y. C. et al. NanoSIMS imaging alteration layers of a leached SON68 glass via a FIB-made wedged crater. Surf. Interface Anal. 46, 233-237 (2014).

36. Smith, W. \& Forester, T. R. DL_POLY_2.0: A general-purpose parallel molecular dynamics simulation package. J. Mol. Graph. 14, 136-141 (1996). 
37. Deng, L. \& Du, J. C. Development of boron oxide potentials for computer simulations of multicomponent oxide glasses. J. Am. Ceram. Soc. 102, 2482-2505 (2019).

38. Du, J. Challenges in molecular dynamics simulations of multicomponent oxide glasses. In: Molecular Dynamics Simulations of Disordered Materials (eds Massobrio C., Du J., Bernasconi M. \& Salmon P.) (Springer International Publishing, 2015).

39. Lu, X., Deng, L., Kerisit, S. \& Du, J. Structural role of $\mathrm{ZrO}_{2}$ and its impact on properties of boroaluminosilicate nuclear waste glasses. NPJ Mater. Degrad. 2, 19 (2018).

40. Rimsza, J. M. \& Du, J. Nanoporous silica gel structures and evolution from reactive force field-based molecular dynamics simulations. NPJ Mater. Degrad. 2, 18 (2018).

\section{ACKNOWLEDGEMENTS}

This work was supported as part of the Center for Performance and Design of Nuclear Waste Forms and Containers, an Energy Frontier Research Center funded by the U.S. Department of Energy, Office of Science, Basic Energy Sciences under Award \# DESC0016584. Some of the experiments were performed using EMSL (grid.436923.9), a DOE Office of Science User Facility sponsored by the Office of Biological and Environmental Research at the Pacific Northwest National Laboratory (PNNL). PNNL is a multi-program national laboratory operated by Battelle for the U.S. DOE under Contract DE-AC05-76RL01830.

\section{AUTHOR CONTRIBUTIONS}

D.E.P., D.K.S., J.V.R. and J.D.V. all contributed to the experimental design of the work presented here. D.E.P. and D.K.S. contributed equally to the execution of experiments and data analysis with assistance from M.G.W. L.D., X.L. and J.D. created the modeled $3 \mathrm{D}$ porous structures. D.E.P. lead the writing of the manuscript with all authors contributing to the final version.

\section{COMPETING INTERESTS}

The authors declare no competing interests.

\section{ADDITIONAL INFORMATION}

Supplementary information is available for this paper at https://doi.org/10.1038/ s41529-020-0110-5.

Correspondence and requests for materials should be addressed to D.E.P. or D.K.S.

Reprints and permission information is available at http://www.nature.com/ reprints

Publisher's note Springer Nature remains neutral with regard to jurisdictional claims in published maps and institutional affiliations.

Open Access This article is licensed under a Creative Common Attribution 4.0 International License, which permits use, sharing, adaptation, distribution and reproduction in any medium or format, as long as you give appropriate credit to the original author(s) and the source, provide a link to the Creative Commons license, and indicate if changes were made. The images or other third party material in this article are included in the article's Creative Commons license, unless indicated otherwise in a credit line to the material. If material is not included in the article's Creative Commons license and your intended use is not permitted by statutory regulation or exceeds the permitted use, you will need to obtain permission directly from the copyright holder. To view a copy of this license, visit http://creativecommons. org/licenses/by/4.0/.

This is a U.S. government work and not under copyright protection in the U.S.; foreign copyright protection may apply 2020 